\title{
Research on Evaluation Index System of College Engineering Talents in Emerging Engineering Based on Onion Model
}

\author{
XiaoPing Wang ${ }^{1}$ \\ School of Education, Tianjin University \\ Tianjin, China
}

\begin{abstract}
In response to a new round of industrial changes, China has actively deployed the construction of Emerging Engineering. This paper sorts out related research of Emerging Engineering, summarizes the new requirements of Emerging Engineering construction for college engineering talents, and uses the onion model as frame to construct the evaluation index system of college engineering talents. The evaluation index system can be divided into 3 first-level indicators, which are knowledge, ability and quality, and further divided into 14 second-level indicators, and 43 third-level indicators.
\end{abstract}

Keywords —emerging engineering; college engineering talents; index system; onion model

\section{INTRODUCTION}

Engineering changes the world [1], Action creates the future. Engineering, as an important factor restricting the development of the country, will attract the attention to all countries in the world in every round of industrial transformation. Since February 2017, China has successively formed three documents of "Fudan Consensus", "Tianda Action" and "Beijing Guide", we will fully explore the Chinese model and Chinese experience that lead the global engineering education and helpto build a strong engineering education. The fundamental purpose of this series of reform actions is to optimize China's higher engineering education to cultivate outstanding engineers that can truly adapt to society and adapt to the future. However, engineering education always lags behind the needs of industry[2]. If the engineering talents cultivated by higher education cannot be properly connected with the social needs, it will undoubtedly cause insufficient talent motivation and slow down the pace of social development. Based on the above reasons, this paper deeply analyzes the connotation of EmergingEngineering in China, and uses the onion model as a theoretical model to try to construct a new engineering university talent evaluation index system that meets China's basic national conditions, and provides a new idea of the cultivation of engineering talents for China.

\section{LITERATURE REVIEW}

The understanding of Emerging Engineering and university engineering talents is the basis for designing the engineering talent evaluation index system, and It is the premise of scientific evaluation of university engineering talents for the background of emerging engineering.

\section{A. What is Emerging Engineering?}

In order to respond to a new round of scientific and technological revolution and industrial transformation, China has proposed a new engineering project named "Emerging Engineering" after proposing a series of national strategies such as "Made in China 2025".In order to better to understand and develop Emerging Engineering, relevant scholars have made different interpretations of this. Starting from the relationship between new engineering and traditional engineering, there is a view that Emerging Engineering is a cross-discipline that is different from traditional engineering [3]. This way of defining EmergingEngineering is very intuitive and easy to understand. However, no matter how it is changed, new forms and new industries cannot be completely separated from the original economic form. The relationship between new engineering and old engineering is very close. Therefore, there is a view that the EmergingEngineering is not completely out of the traditional engineering. "Emerging" is a new development of the old engineering, including the three aspects of this [4]. In addition to the above interpretation, there are also viewing that Emerging Engineering is a new way of cultivating talents. The connotation of the Emerging Engineering department is to cultivate outstanding engineering talents for high moral character as the core and focus on his diversification and innovation [5]. There are also opinions to understand Emerging Engineering from the perspective of different fields. This definition expands the cognitive horizon and breadth of Emerging Engineering from two different perspectives of university and society [6]. It also reveals the comprehensiveness of Emerging Engineering from one side, which can be understood as the innovation and progress of science, applied science, engineering science and engineering practice, the intersection and blending of different disciplines, and the formation of new engineering disciplines or fields, new paradigms and new engineering. Comprehensive concepts such as education, it means a comprehensive concept including a new engineering discipline or field, a new paradigm, and a new engineering education,etc. [7]

\section{$B$. What is university engineering talents?}

The Outline of National Medium \& Long-Term Program for Talent Development Plan states: "Talent refers to those who have certain professional knowledge or expertise, carry out creative work and contribute to society, and are laborers with high ability and quality in human resources [8].’'This definition not only emphasizes that talents should have certain professional knowledge andskills, but also highlights the two 
key talents for "ability" and "quality". Higher engineering education is based on technical science as the discipline, characterized by the research and application of engineering science and technology, facing the actual needs of engineering, and cultivating professional technical education of advanced engineering and scientific talents with innovative and practical ability [9].

Therefore, engineering talents should be excellent engineering talents cultivated by higher engineering education. What abilities and qualities do excellent engineers need? What kind of engineers should we cultivate in engineering education?

\section{THEORETICAL FRAMEWORK}

In the 1970s, American psychologist McClelland believed that academic performance could not effectively predict professional achievement, so the concept of "Competency" was proposed to predict individual performance. The onion model is one of the competency models. In 1982, Richard Boyatzis proposed the " onion model " (Fig1). The model emphasizes the weight of competency traits. The most critical traits are placed in the core of the onion model, including motivation or traits. This is the deepest level of personality; Wrapped in a layer outside the core, it reflects the mediating effect, including self-image, social role, attitude and values. It is the core trait of human beings, which is further tempered in work and life. They have strong stability and can affect human behavior; The outermost layer is more susceptible to change, including knowledge and skills. In the onion model, the outer layer to the inner layer gradually deepens. The characteristics contained inside are more stable and difficult to observe and change, and the characteristics contained in the outside are easily changed. Therefore, university engineering talents are excellent engineering talents cultivated by higher engineering education. They should have the application of engineering technology and other relevant knowledge in the professional field. They can solve engineering and technical problems, and contribute to the society through applied research and innovative development.

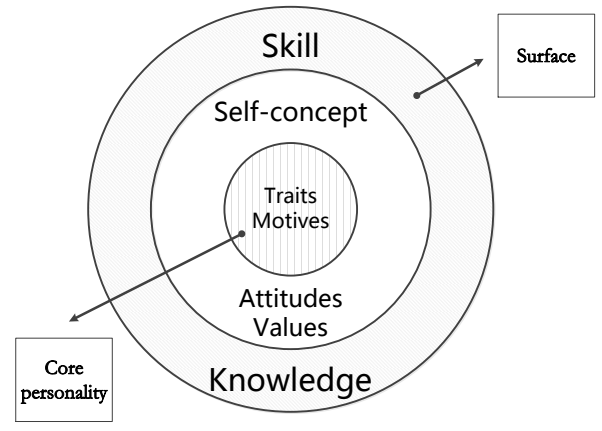

Fig. 1 Onion model

It can be clearly seen from the above analysis that the purpose of higher engineering education is to train engineering talents that meet market needs and have competent positions.

Therefore, this study takes the onion model as the theoretical model. In the process of constructing the engineering talent evaluation index system, we pay attention to the weight of each level factor in the process of constructing the evaluation index system of engineering talents. Firstly, the evaluation index elements of engineering talents forEmergingEngineering are divided three levels from explicit about implicit (Fig2). First, the theoretical knowledge required by new engineering talents; second, the comprehensive ability of new engineering talents; third, the overall quality of engineering talents forEmergingEngineering education, and the construction of EmergingEngineering based on the relationship between the elements College engineering talent onion model. The matching of people and work posts is the fundamental purpose of the training objectives of higher engineering education. Therefore, the evaluation index system of engineering talents for colleges should start from the needs of posts and take the post ability as the coreof the background of Emerging Engineering. Based on this, this paper constructs the framework of university engineering talent evaluation index system under the background of Emerging Engineering with the onion model as the framework.

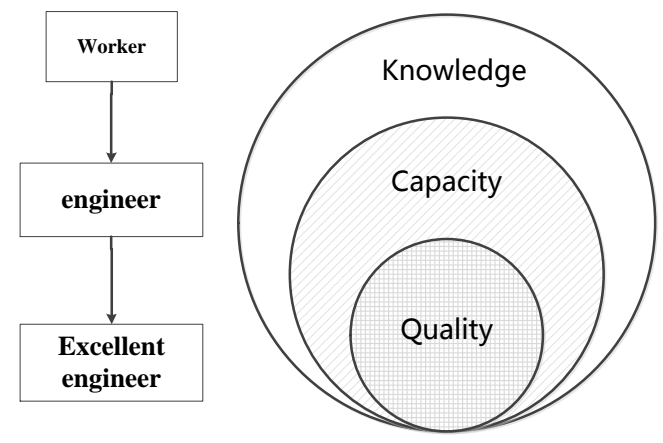

Fig. 2 Onion model of Emerging Engineering talents

The onion model reflects the composition of the talent's quality, merging the individual's quality characteristics into a competency combination, and emphasizing the relationship between the different levels of constituent elements. The progressive pattern reflects the difficulty of cultivating and measuring each element. Therefore, In the process of constructing the evaluation index system of engineering talents, we pay attention to the weight of each level factor. Firstly, the talent evaluation index elements are divided into three levels from explicit about implicit: 1)The theoretical knowledge required by emerging engineering talents; 2)The comprehensive ability of emerging engineering talents; 3 )The quality of emerging engineering talents, and based on the relationship between the elements built anonion model of emerging engineering talents. In the process of constructing the evaluation index system of engineering talents for Emerging Engineering education, we must insist the people-oriented concept firstly, insist the core requirements of new engineering construction, and combine the characteristics of the industry to design evaluation indicators for engineering talents for Emerging Engineering education. The talent evaluation index system includes 3 first-level indicators, 14 second-level indicators and 43 third-level indicators. Each level 1 indicator is described in detail below. Then we will detail the content of each level indicator. 


\section{The Design of EVALUTION InDEX System}

In theindustry 4.0era, excellent engineers not only need solid theoretical knowledge, skilled professional skills, and good ethical quality, but also some more critical capabilities and qualities:1) The ability of cross-fusion, In the information age, knowledge is not isolated. If there is progress and breakthrough, it is necessary to continuously promote the mutual collision and integration of different disciplines. Therefore, excellent engineers must have a complete knowledge system and have relevant knowledge reserves and capabilities for cross-border integration. 2) Engineering practice ability.If we only pay attention to theoretical training, we can only cultivate rigorous theorists rather than excellent doers. Engineering has strong practicality. In the face of complex and diverse practical problems, it is not enough to have a theoretical foundation. Engineers must be able to solve real-life problems, and must have excellent engineering practice capabilities.3) Innovation ability.Only innovation can achieve real development.All in all, the core mission of the Emerging Engineeringeducation is to cultivate outstanding engineering talents for the ability to inherit innovation and cross-integration, so as to meet the needs of talents for social development.

\section{A. Knowledge}

Knowledge refers to information that a person has about a particular field of theory or practice.Due to the multidisciplinary and multidisciplinary nature of engineering,it determines that engineering talents should be a compound talent for a multi-faceted knowledge reserve.The cultivation of Emerging engineering talents must go beyond the "narrow knowledge" and "narrow to knowledge" gap.From the related research on the knowledge structure of engineering talents, it is not enough for an excellent engineer to have only subject knowledge.The breadth and depth of knowledge is important factors influencing the future development of engineers, so other disciplines are equally important.Because the engineering cannot exist independently on culture, its development is affected by social, economic and cultural aspects.In addition, the traditional engineering talent knowledge evaluation system is easy to ignore the real work situation about engineering industry. Only by grasping the development trend of the industry and understanding the laws governing the development of the industry can students not are eliminated from rapidly changing industries.Students will not be eliminated from the rapidly changing industry if they can grasp the development of the industry and understand the rules of industry development.Therefore, this study specifically divides the knowledge structure of:1)Basic knowledge; 2)Engineering expertise; 3) Industry background knowledge.
1) Basic knowledge

- Have the relevant math and natural science knowledge required for engineering work.

- Have certain economic management and other humanities and social science knowledge.

2) Engineering expertise

- Master the basics of engineering knowledge.

- Understand production processes, equipment and manufacturing systems.

- Understand the development status and trends of this major.

3) Industry background knowledge

- Understand industry standards.

- Understand the market situation.

\section{B. Capacity}

Competence refers to the psychological conditions for the smooth implementation of activities, including the psychological conditions for the smooth mastery of knowledge and skills, which indicates the level of achievement that people can achieve in their activities. When constructing the talent evaluation indexes system, the reason for taking the"capacity"as the first-level indicator is that a reasonable and perfect capacity structure is a necessary condition for the EmergingEngineering talents to carry out all creative activities.EmergingEngineering's requirements for talent capabilities include not only the skills of specific technologies acquired through non-cognitive practice, but also the ability to gain further potential through cognitive practice [10].Based on this, this study further divides the ability into seven secondary indicators, including:1)Informationliteracycompetency; 2)Lifelong learning skill; 3)Innovation and entrepreneurship; 4)Interpersonal skill;5)Crossover collaborationskill; 6)Engineering practice ability;7)Engineering leadership ability.

1) Information literacy competency

- Ability to understand information.

- Ability to access information.

- Ability to analyze information.

- Ability to manage information.

- Ability to use information effectively.

- Information ethical awareness.

2) Lifelong learning skill

Lifelong learning is a key competency required for professional development.

- Have a strong sense of self-study and self-study ability.

- Have a close and continuous awareness of the development of the discipline and be able to understand 
the frontier research and future development prospects of the discipline.

- Be able to actively accept new technologies and methods and predict their impact on future development.

- Ability to adapt to career development and industry changes.

\section{3) Innovation and entrepreneurship}

Innovation and entrepreneurship are the requirements of the new era and the requirements for the reform and development of higher education

- Have a strong sense of innovation.

- Have the comprehensive ability to use knowledge and theory to complete the innovation process and produce innovative results.

- Ability to use knowledge and experience to solve problems innovatively, thereby generate new ideas, new methods, new schemes and new achievements.

4) Interpersonal skills

The ability of individual interpersonal communication is very important. It is difficult to adapt to the society only by relying on individuals. Therefore, it is very important to have the awareness of cooperation in the team.

- Havegood communication skill.

- Have good team working ability.

5) Crossover collaboration skill

In order to implement reforms, we must break with the discipline ecology.

- Have strong interdisciplinary integrationability.

- Havestrongcross-industry transformation and integrationability

\section{6) Engineering practical ability}

It is necessary to pay attention to the practical ability of engineering talents for colleges, and further develop students' practical ability to solve complex engineering problems.

- Ability to analyze and solve problems.

- Ability to design, implement, and maintain engineering entities using engineering thinking and theoretical knowledge of engineering expertise.

\section{7) Engineering leadership ability}

Engineers needto develop in an all-round way and become leaders in their industry. They need to attract and influence internal members and achieving organizational goals better.

- Basic leadershipskill.

- Havestrong technical leadership.
- Ability to attract and influence members and stakeholders within the organization in engineering practice.

- Ability to exert talent and personal influence in the process of achieving organizational goals.

\section{Quality}

Quality is the foundation of the people, and it is the fundamental guarantee of the all-round development of talents.The difference between ordinary engineers and excellent engineers is not only reflected in the external performance of knowledge and ability, but also incharacter and attitude of the individual.We must not only pay attention to the development of students' knowledge and ability, but also the growth of students' quality and pay attention to the overall development of students.The evaluation of the quality of engineering talents forEmergingEngineering education is not only limited to the investigation into students' professional ethics, but also pays attention to the investigation into students' sense of responsibility. They need to have a sense of self-responsibility, a high sense of responsibility for society and a high sense of national identity. Emerging engineering talents should have a global vision, attach importanceof the development of the world, and contribute their own strength to the development of the world.In addition, new ideas should be integrated into the engineering field to achieve green engineering and sustainable engineering.Based on this, the study divides the quality of four secondary indicators, including: 1)Professional ethics; 2)Patriotism; 3)Global perspective;4)Modern engineering consciousness.

1) Professional ethics

- Ability to follow professional norms, ethical standards and ethical qualities of the industry at work.

- Have the right values.

2) Lifelong learning skill

- Have a high sense of social responsibility.

- Have a high sense of national identity, belonging and mission.

3) Global perspective

- Have a broad international perspective.

- Have the right international perspective.

- Have the open concept of internationalization.

4) Modern engineering consciousness

- Have a good sense of quality, safety and efficiency.

- Have a good sense of service.

- Have a good ecological awareness.

- Have a good sense of rule of law.

- Have a good engineering ethic awareness. 
- Have a strong critical thinking.

\section{SUMMARY}

From the perspective of the development of engineering education in China, engineering education has always focused on the practicality of disciplines and often ignores the needs of human on the influence of instrumental rationalism. Although engineering is a specific application of science and technology, it is actually a response to human "demands". How to better to meet the needs of human is the ultimate goal pursued by engineering education. While respecting the practicality of engineering education is very important, focusing only on one aspect of engineering education can lead to a loss of balance in the education system. Therefore, the evaluation of the quality of talents can not only proceed with the discipline, but also should be based on the role of human to design the index to achieve the all-round development of students. The elements of a superior engineer should possess are including: knowledge, ability and quality from explicit to implicit. These three elements constitute a stable structure of evaluating talents and they are indispensable. Engineering talent evaluation in Emerging Engineering education is a systematic project, the onion model provides an idea of the construction of university engineering talent evaluation index system. It also provides a reference to the cultivation of engineering talents for colleges under the background of EmergingEngineering.

\section{REFERENCES}

[1] Zhang Fengbao. The Paradox of the Path and Method of Emerging Engineering Construction-Exploration and Practice of Tianjin University[J]. University Teaching in China,2017(07):8-12.(In Chinese)

[2] Zhu Zhengwei, Li Maoguo. Research on the Development Strategy of Chinese Engineering Education Facing the New Industrial Revolution[J]. China Higher Education Research, 2018(03): 44-50.(In Chinese)

[3] Ma Luting. University should pay attention to the construction of subject groups [J]. China Higher Education, 2017(10): 35-38.(In Chinese)

[4] Lin Jian. Future-oriented construction of EmergingEngineering in China[J]. Education Research of Tsinghua University, 2017(02):26-35.(In Chinese)

[5] Zhong Denghua. The Connotation and Action of Emerging Engineering Construction[J]. Higher Education Research, 2017(3):1-6.(In Chinese)

[6] Emerging Engineering: A new revolution in engineering education? $\begin{array}{llll}\text { News } & \text { Science Network [EB/OL]. [2019/5/16]. }\end{array}$ http://news.sciencenet.cn/htmlnews/2017/3/370533.shtm. (In Chinese)

[7] $\mathrm{Gu}$ Peihua. Emerging Engineering and New Paradigm: Concept, Framework and Implementation Path[J]. Higher Engineering Education Research, 2017(06): 1-13. (In Chinese)

[8] Outline of National Medium- and Long-Term Talent Development Plan [M]. Beijing: People's Publishing House, 2010: 42 pages. (In Chinese)

[9] Shi Huamin. Research on the Construction of Quality Evaluation System for Talents Training in Higher Engineering Education [D]. Harbin University of Science and Technology, 2013. (In Chinese)

[10] Jiang Xiaokun, Zhu Wei, Li Zhiyi. New Mode of Talent Cultivation in Emerging Engineering[J]. Higher Education Development and Evaluation, 2018, 34(02): 17-24. (In Chinese) 